Eixo Temático: Processos de Ensino-Aprendizagem

\title{
ET-06-001 \\ O ENSINO DE CIÊNCIAS E A EDUCAÇÃO EM SAÚDE: PRÁTICAS SIGNIFICATIVAS EM UMA ESCOLA ATENDIDA PELO PIBID/BIOLOGIA DA UFPB CAMPUS I
}

Jonatas Pereira de Limaํㅡㄹ Caliandra Maria Bezerra Luna Lima², Eliete Lima de Paula Zárate³, Maria de Fátima Camarotti ${ }^{4}$

${ }^{1}$ Graduando de Ciências Biológicas e bolsista PIBID Biologia, Campus I - UFPB.

${ }^{2}$ Professora Departamento de Fisiologia e Patologia, Campus I CCS/UFPB.

${ }^{3}$ Professora do Departamento de Ecologia e Sistemática, Campus I CCEN/UFPB e Coordenadora PIBID Biologia Campus I - UFPB.

${ }^{4}$ Professora do Departamento de Metodologia da Educação, Campus I CE/UFPB e Coordenadora PIBID Biologia Campus I - UFPB.

http://dx.doi.org/10.21472/congrebio2016.et-06-001

\section{RESUMO}

O PIBID é um importante programa que permite a integração entre a teoria e a prática no processo de formação inicial dos futuros docentes. Uma das licenciaturas atendidas é a de Ciências Biológicas onde o aluno de graduação terá a oportunidade de atuar com alunos da educação básica, por meio das disciplinas de Ciências e Biologia. O estudo teve como objetivo realizar intervenções pedagógicas como forma de contribuir para o processo de ensinoaprendizagem dos estudantes com ênfase na doença Ancilostomíase, com a utilização de diferentes metodologias. Utilizou-se como pressupostos teórico-metodológicos, os fundamentos da Pesquisa Qualitativa e Quantitativa, através do Método Etnográfico com elementos da Etnografia Escolar e Observação Participante. A coleta de dados ocorreu através da aplicação de questionários pré e pós-testes. A pesquisa foi realizada com alunos $(\mathrm{n}=252)$ do $6^{\circ}$ e $7^{\circ}$ anos do Ensino Fundamental II do Centro Estadual Experimental de Ensino-Aprendizagem Sesquicentenário, localizado na cidade de João Pessoa (PB). Em seguida foi realizada a intervenção pedagógica com aulas expositivas dialogadas, produção textual e jogo lúdico. Através da utilização desses recursos observou-se o interesse, participação e o envolvimento dos alunos nas atividades realizadas no ambiente escolar. Por meio do questionário pré-teste e pósteste aplicados percebeu-se resultados satisfatórios e assim foi possível concluir que a educação em saúde associada com diferentes estratégias didáticas, é uma excelente alternativa que traz benefícios ao processo de ensino-aprendizagem dos estudantes, promovendo a sensibilização e reforçando as medidas de profilaxia (CAPES).

Palavras-chave: Saúde escolar; Parasitologia; PIBID.

\section{INTRODUÇÃO}

O Programa Institucional de Bolsa de Iniciação à Docência (PIBID) é um programa institucional que atua em conjunto com universidade e escolas da rede pública brasileira, com a intenção que os estudantes de licenciaturas, de diferentes áreas, exerçam atividades pedagógicas e assim contribuam para a melhoria da qualidade educacional brasileira. Ao encarar o ambiente escolar o aluno de licenciatura tem a oportunidade de observar e atuar na realidade escolar, possibilitando, sobretudo uma troca de aprendizado entre os professores experientes (BRASIL, 2012; BATISTA e BITTENCOURT, 2015). 
Apesar de ser uma iniciativa recente, o PIBID torna-se importante à medida que permite que haja uma integração entre a teoria e a prática no processo de formação inicial dos licenciandos, visto que atividades na área de extensão possibilitam assim um processo contínuo que vai além da universidade - escolas públicas, perpassando pela sociedade de modo geral (PRODÓCIMO et al., 2015; SANTOS et al., 2015).

Nesse contexto, uma das licenciaturas atendidas pelo PIBID é o curso de Ciências Biológicas, onde o aluno de graduação tem a oportunidade de atuar com alunos da educação básica, por meio das disciplinas de Biologia, voltados para o $1^{\circ}$ ao $3^{\circ}$ anos do ensino médio e Ciências Naturais, onde atuam com as séries do $6^{\circ}$ ao $9^{\circ}$ anos do Ensino Fundamental II. O aprendizado do conteúdo de Ciências e Biologia são fundamentais para a formação de um cidadão proativo.

No que diz respeito às aulas de Ciências, objetiva-se permitir ao aluno a possibilidade de atribuir significados, teorias, aspectos históricos e culturais presentes nas ciências. Diante disso, é importante ressaltar que o ensino de Ciências fornece aos estudantes a capacidade de colocar em prática a cidadania de forma crítica em uma sociedade onde é crescente a atualização e abordagem de novos conteúdos (CASTRO e COSTA, 2011).

Seguindo esse pensamento, é importante ressaltar que o ensino de Ciências valoriza a relação entre os conteúdos da ciência, a tecnologia e a sociedade de um modo geral. Porém, o que é visto em grande parcela das escolas é o uso do método tradicional, que apesar das crescentes inovações tecnológicas, continua a persistir de modo que ocorre pouca contribuição para o processo de ensino-aprendizagem de estudantes, visto que são apenas meros receptores de informações (PEREIRA, 2009).

O ensino de Ciências voltado para a realidade dos alunos permite uma aprendizagem efetiva e transformadora, onde o procedimento utilizado pelo professor viabiliza uma curta segurança em conteúdos básicos para a vivência diária dos alunos, desenvolvendo a capacidade de posicionar-se diante das questões que interferem na sua vida e na coletividade (LIMA et al., 2015).

Um dos conteúdos presentes no ensino de Ciências são as doenças causadas por helmintos, presente no conteúdo programático dos $6^{\circ}$ e $7^{\circ}$ anos do Ensino Fundamental II. Essas doenças são um dos principais problemas da saúde pública, visto que são indicadores do desenvolvimento socioeconômico de um país, provocando uma série de problemas nos principais acometidos, que são justamente as crianças em idade escolar, sendo responsável por um enorme prejuízo que pode ser percebido em seu rendimento escolar (FONTENELE, 2015).

Sabendo que a grande quantidade de infecções causadas por helmintos pode refletir na qualidade de vida da população, é importante que se possam romper as formas de transmissão e disseminação desses seres, onde muitas vezes existe o desconhecimento por parte da população das medidas de controle e da prevenção. Desse modo, é importante destacar a importância de se trabalhar estas doenças com crianças em idade escolar, uma vez que ao ensinar e sensibilizá-los poderá contribuir para que sejam disseminadores e multiplicadores do conhecimento adquirido no ambiente escolar levando as informações para amigos, familiares e comunidade (GOMES et al., 2015).

A educação em saúde atua como um processo de ensino-aprendizagem que tem como objetivo a promoção da saúde, desse modo atua como um facilitador das descobertas dos sujeitos envolvidos sobre a realidade da qual faz parte. Nesse contexto é uma excelente ferramenta para propor melhoria e qualidade de vida das pessoas. Através das intervenções pedagógicas, é possível romper modelos educacionais tradicionais e inovar em sala de aula em especial, para a população que não tem acesso a informação (OLIVEIRA et al., 2015; GAZZINELLI et al., 2005).

Gomes et al. (2015) informam que é necessário utilizar as políticas de atenção voltadas para a infância com o intuito de diminuir as situações de vulnerabilidade e contribuir para uma qualidade de vida em conjunto com intervenções educativas, buscando sempre um sujeito crítico e ativo no cuidado de sua saúde. 


\section{OBJETIVOS}

O estudo teve como objetivo realizar um trabalho educativo como forma de contribuir para o processo de ensino-aprendizagem dos estudantes através da sensibilização e prevenção das Parasitoses Humanas, com ênfase na doença Ancilostomíase em conjunto com a utilização de diferentes metodologias facilitadoras para despertar os cuidados de promoção e educação a saúde.

\section{METODOLOGIA}

A realização dessa pesquisa buscou como pressupostos teórico-metodológicos, os fundamentos da Pesquisa Qualitativa e Quantitativa, através do Método Etnográfico com elementos da Etnografia Escolar e Observação Participante. A coleta de dados ocorreu através de questionários pré e pós-testes.

Na pesquisa qualitativa, o pesquisador desempenha diversas funções ao mesmo tempo, fazendo o papel de sujeito e objeto da pesquisa, além disso, pode ter as características de tentar compreender os significados proporcionados pelos entrevistados. Enquanto que a pesquisa quantitativa, nas áreas da saúde, domina o estudo do número de casos em um dado intervalo numa população e assim é possível avaliar os riscos e tendências de agravos e ameaças (RICHARDSON, 2010).

O Método Etnográfico com elementos da Etnografia Escolar possibilita uma abordagem de campo, onde é possível perceber, descobrir e entender a realidade escolar e suas formas de constituição por meio de experiências e descrições bem elaboradas através dos participantes do processo educacional. Por meio da observação-participante permite ao observador assumir o papel e os seus objetivos de estudo são revelados ao grupo o qual será estudado (BEZERRA et al., 2006).

O presente trabalho foi realizado no Centro Estadual Experimental de EnsinoAprendizagem Sesquicentenário (CEEEA Sesqui.), João Pessoa, PB, com oito turmas do $6^{\circ}$ e $7^{\circ}$ ano do Ensino Fundamental II, tendo como público alvo em torno de 250 alunos na faixa etária de 11 a 14 anos. O trabalho foi desenvolvido durante os meses de agosto a outubro de 2015.

Inicialmente, no mês de agosto de 2015, foi aplicado um questionário pré-teste sobre a Ancilostomíase, contendo questões relacionadas ao agente etiológico, nome popular, morfologia, transmissão, sintomas e profilaxia. O questionário serviu inicialmente para conhecer as concepções prévias dos alunos no que diz respeito à doença que seria estudada. Em seguida foi desenvolvida a intervenção referente à Ancilostomíase, dividida da seguinte maneira:

1. Aula expositiva dialogada com auxílio de recursos didáticos (modelos didáticos em porcelana fria, vídeo educativo, história e cartilha educativa);

2. Leitura de texto (O Jeca Tatu e o Amarelão), produção textual, caça-palavras e cruzadinha;

3. Jogo didático (O Jogo do Amarelão)

\section{RESULTADOS E DISCUSSÃO}

Os 252 alunos foram avaliados por meio do questionário pré-teste como forma de verificar os conhecimentos prévios sobre a doença Ancilostomíase (Tabela 1). Após a análise dos dados, observou-se que quando questionados a respeito do nome popular da doença Ancilostomíase, $10 \%$ dos alunos responderam corretamente, $64 \%$ optaram por respostas incorretas e $26 \%$ não sabiam a respeito. Em seguida, foram questionados sobre a transmissão da helmintíase e $15 \%$ dos alunos responderam corretamente; com relação às respostas incorretas, $44 \%$ dos alunos responderam de forma errada e $41 \%$ não souberam responder. 
Quando questionados sobre os sintomas da Ancilostomíase, 56\% dos estudantes desconheciam o principal sintoma da doença, enquanto $15 \%$ responderam incorretamente e $29 \%$ informaram o sintoma corretamente. Em outra questão a respeito das medidas profiláticas da Ancilostomíase, $49 \%$ dos estudantes afirmaram desconhecer as medidas para evitar os vermes Ancylostoma duodenale e Necator americanus, enquanto que $21 \%$ responderam de forma correta e $30 \%$ responderam incorretamente.

Tabela 1. Respostas do pré-teste, em agosto de 2015, com alunos das oito turmas do $6^{\circ}$ e $7^{\circ}$ anos do CEEEA Sesqui, em João Pessoa-PB.

\begin{tabular}{cccc} 
Ancilostomíase & \multicolumn{3}{c}{ Respostas } \\
\cline { 2 - 4 } Pré-Teste (24/08/2015) & Correta & Incorreta & Não sabe \\
opular da doença Ancilostomíase? & $10 \%$ & $64 \%$ & $26 \%$ \\
s pegar a doença Ancilostomíase? & $15 \%$ & $44 \%$ & $41 \%$ \\
al sintoma da Ancilostomíase? & $29 \%$ & $15 \%$ & $56 \%$ \\
as de prevenção para evitar a Ancilostomíase? & $21 \%$ & $30 \%$ & $49 \%$ \\
\hline
\end{tabular}

Após a aplicação do questionário pré-teste, foi iniciado a intervenção pedagógica (Figura 1), foi introduzido em sala de aula o conteúdo a respeito da Ancilostomíase e Bicho geográfico com auxílio de slides no data show, rico em imagens ilustrativas, além do uso de modelos didáticos feitos a partir da massa de porcelana fria, ilustrando a morfologia de parte do ciclo biológico da doença (ovos e os vermes Ancylostoma duodenale e Necator americanus), além disso, foram utilizados modelos tridimensionais que ilustravam os ciclos biológicos das doenças.
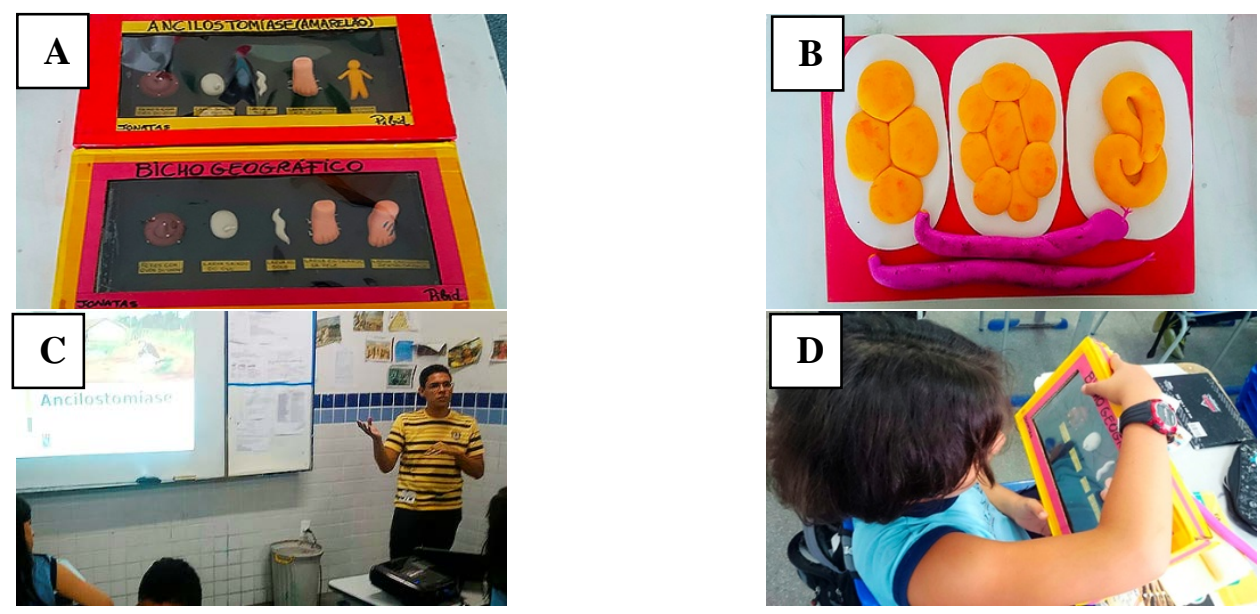

Figura 1. Aula dialogada sobre a ancilostomíase com auxilio de recursos didáticos, com alunos das oito turmas do $6^{\circ}$ e $7^{\circ}$ anos do CEEEA Sesqui, em João Pessoa-PB. A- Ciclo biológico: ancilostomíase e bicho geográfico. B- Modelo didático em massa de porcelana fria: ovos e Ancylostoma duodenale (macho e fêmea). C- Aula expositiva dialogada auxiliada por data show. D- Aluno observando o ciclo biológico.

Foi notável a importância dos modelos didáticos como recurso para auxiliar o processo de ensino-aprendizagem dos alunos. Durante o momento da aula dialogada, os alunos tiveram contato com os modelos e assim observaram e diferenciaram a morfologia dos vermes macho e fêmea do Ancylostoma duodenale e Necator americanus. Nesse sentido Aguiar (2015), afirma que os modelos didáticos auxiliam os alunos na visualização de um conceito complexo e abstrato, onde é possível comparar diferentes estruturas, formas e funções, além de explorar 0 desenvolvimento visual, estético e sensório-motor e sempre aproximando da realidade. 
Durante a aula expositiva dialogada os estudantes receberam cartilhas educativas (Figura 2) com informações a respeito da morfologia, habitat, transmissão, ciclo biológico, sintomas, profilaxia e curiosidades a respeito da Ancilostomíase. Em seguida, foi realizada uma leitura da história de Jeca Tatu. Durante esse momento, foi solicitado que os alunos realizassem a leitura em sala de aula e em seguida deveriam interpretar e responder alguns questionamentos referentes à história. Esse momento foi bastante atrativo, visto que muitos desconheciam o famoso personagem da obra de Monteiro Lobato.

Sabe-se a importância que a leitura pode promover no leitor, justamente por desenvolver um senso crítico e autônomo, vale salientar que cabe ao docente ampliar a capacidade leitura do seu aluno, através de estratégias e gêneros que possam estimular o hábito pela leitura (LOPES, 2016).

Após a leitura do texto, foi introduzido no ambiente o uso de palavras-cruzadas e caçapalavras referente à Ancilostomíase. Foi um momento bastante agradável e realizado fora da sala de aula e tiveram a cartilha didática como auxílio. O uso de estratégias de ensino que favoreçam a aprendizagem e que possam integrar diversos sentidos auxilia e é fundamental ao processo de ensino-aprendizagem (MORAES; TORRES, 2004).
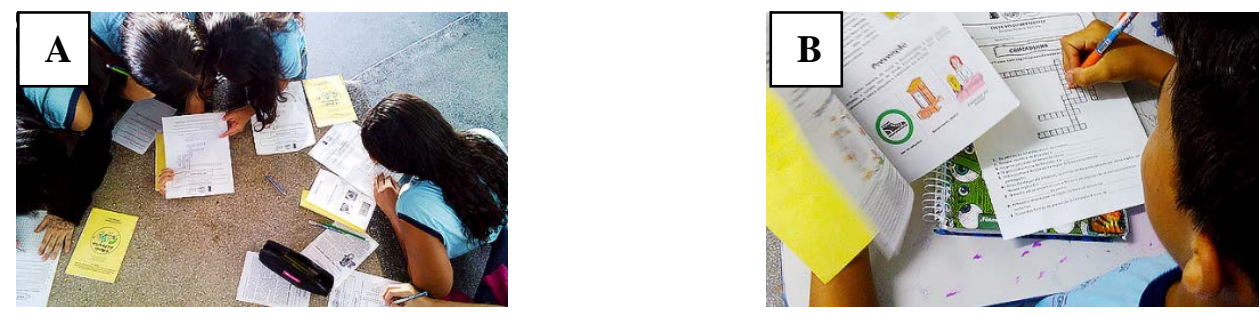

Figura 2. Intervenção pedagógica com diferentes recursos didáticos, com alunos das oito turmas do $6^{\circ}$ e $7^{\circ}$ anos do CEEEA Sesqui, em João Pessoa-PB. A- Grupo de alunos do $7^{\circ}$ ano realizando o caça-palavras; B- Aluno do $6^{\circ}$ ano respondendo a cruzadinha com apoio da cartilha educativa.

Para concluir a etapa da intervenção pedagógica sobre a doença Ancilostomíase, foi desenvolvido e elaborado um jogo didático (Figura 3) denominado "O Jogo do Amarelão", onde os alunos eram divididos em cinco equipes, cada equipe recebia "um pé descalço com uma cor diferente", fazendo alusão à forma como a doença era transmitida e ao final do jogo receberia "um par de calçados" como prêmio. Durante a execução do jogo, foi um momento bastante proveitoso, onde os alunos estavam bastante entusiasmados e competitivos.

De acordo com Pereira (2009), os jogos didáticos permitem ao aluno superar etapas de seu desenvolvimento psicoemocional, auxilia na socialização e interação, permitindo a criação de espaços para a promoção de novas formas de conhecimentos por serem atividades lúdicocriativas. A ludicidade é uma importante ferramenta para o processo de ensino-aprendizagem, a sua utilização proporciona ao aluno, motivação, com a qual é possível tornar a aula dinâmica e agradável, resultando assim em um melhor rendimento (PASSARELLI, 2012). 

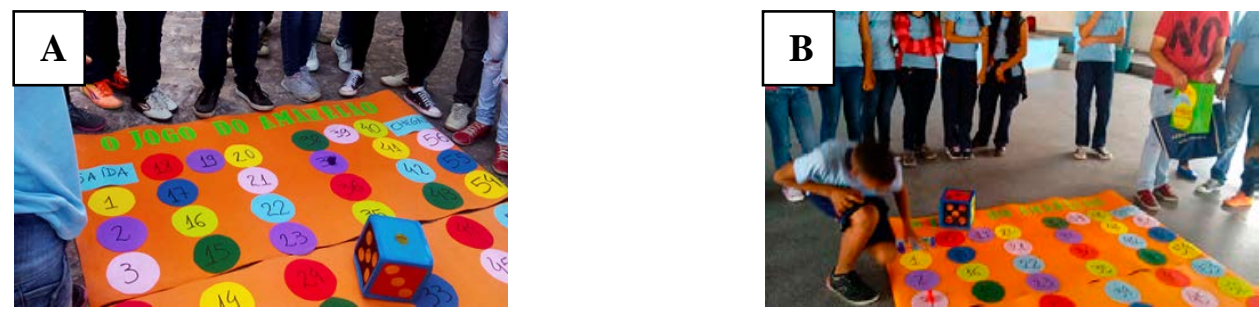

Figura 3. Jogo didático realizado com alunos das oito turmas do $6^{\circ}$ e $7^{\circ}$ anos do CEEEA Sesqui, em João Pessoa-PB. A: Alunos do $6^{\circ}$ ano; B: Alunos do $7^{\circ}$ ano.

Ao final da intervenção pedagógica dividida em três etapas, foi aplicado o questionário pós-teste (Tabela 2), com o total de 248 alunos. Após a realização das intervenções ouve um aumento satisfatório no que diz respeito à análise dos dados. Quando perguntados sobre o nome popular da doença Ancilostomíase, foi observado que 93\% dos alunos responderam de forma correta, 3\% responderam incorretamente e $4 \%$ não souberam responder. No que diz respeito como a Ancilostomíase pode ser transmitida ao ser humano, 88\% dos estudantes responderam corretamente, enquanto que $9 \%$ responderam de maneira errada e $3 \%$ não souberam responder.

Tabela 2 - Respostas do pré-teste, em setembro de 2015, com alunos das oito turmas do $6^{\circ}$ e $7^{\circ}$ anos do CEEEA Sesqui. em João Pessoa-PB.

\begin{tabular}{|c|c|c|c|}
\hline \multirow{2}{*}{$\begin{array}{c}\text { Ancilostomíase } \\
\text { Pós-Teste (21/09/2015) }\end{array}$} & \multicolumn{3}{|c|}{ Respostas } \\
\hline & Correta & Incorreta & Não sabe \\
\hline 1. Qual o nome popular da doença Ancilostomíase? & $93 \%$ & $3 \%$ & $4 \%$ \\
\hline 2. Como podemos pegar a doença Ancilostomíase? & $88 \%$ & $9 \%$ & $3 \%$ \\
\hline 3. Qual o principal sintoma da Ancilostomíase? & $88 \%$ & $10 \%$ & $2 \%$ \\
\hline 4. Quais a medidas de prevenção para evitar a Ancilostomíase? & $91 \%$ & $6 \%$ & $3 \%$ \\
\hline
\end{tabular}

Em relação ao principal sintoma da Ancilostomíase 88\% dos estudantes responderam corretamente, enquanto $10 \%$ responderam incorretamente e $2 \%$ não souberam responder a pergunta. Por fim com relação à profilaxia da Ancilostomíase $91 \%$ dos estudantes responderam de forma correta, $6 \%$ responderam incorretamente e $3 \%$ desconhecer às medidas para evitar os helmintos transmissores da ancilostomíase.

\section{CONCLUSÃO}

Pode-se constatar que os resultados obtidos na pesquisa foram satisfatórios e é possível destacar a importância da educação em saúde no ensino de Ciências. Por meio do uso de diferentes estratégias didáticas foi possível fazer diferente e possibilitar uma aprendizagem significativa, propiciando aos alunos, da educação básica, o contato com uma prática pedagógica diferenciada e assim formar multiplicadores do conhecimento científico.

\section{REFERÊNCIAS}

AGUIAR, L. C. C. Modelos biológicos de porcelana fria. In: SANTORI, R. T; SANTO, M.G. Ensino de Ciências e Biologia: um manual para elaboração de coleções didáticas. 1. ed. Rio de Janeiro: Interciência, 2015. p. 55-75. 
BATISTA, P. H.; BITTENCOURT, R. L. Contribuições do PIBID na formação de professores a partir das três bases do novo modelo de formação de António Nóvoa. Anais... SEMINÁRIO DE EDUCAÇÃO, CONHECIMENTO E PROCESSOS EDUCATIVOS, 2015. v. 1.

BRASIL. Coordenação de Aperfeiçoamento de Pessoal de Nível Superior. Diretoria de Educação Básica Presencial. PIBID - Relatório de Gestão 2009-2011, 2012.

BESERRA, E. P; ARAÚJO, M. F. M; BARROSO, M. G. T. Promoção da saúde em doenças transmissíveis: uma investigação entre adolescentes. Revista Acta Paul Enferm, 2006.

CASTRO, B. J.; COSTA, P. C. F. Contribuições de um jogo didático para o processo de ensino e aprendizagem de Química no Ensino Fundamental segundo o contexto da Aprendizagem Significativa. Revista Electrónica de investigación en Educación en Ciencias, v. 6, n.6, 2011.

FONTENELE, M. G. M.; MORAIS, A. M.; MIRANDA, T. R.; ALCANTARA, F. L. C.; LEAL, J. C. S.; SILVA, J. F. M.; FERREIRA JÚNIOR, A. R. Uma Intervenção para a Prevenção de Parasitos na Infância. SANARE-Revista de Políticas Públicas, v. 14, Supl. 1, p. 35, 2015. <https://sanare.emnuvens.com.br/sanare/article/view/659/362>. Acesso em: 25 mar. 2016.

GOMES, A. M.; SANTOS, M. S.; FINGER, D.; ZANITTINI, A.; FRANCESCHI, E. V.; SOUZA, J. B.; HAAG, F. B.; SILVA, D. J. Refletindo sobre as práticas de educação em saúde com crianças e adolescentes no espaço escolar: um relato de extensão. Revista Conexão UEPG, $\quad$ v. 11, $\quad$ n. 3, $\quad$ p. 332-341, $2015 . \quad$ Disponível em: <http://www.revistas2.uepg.br/index.php/conexao/article/view/7592/4808>. Acesso em: 25 mar. 2016.

LIMA, J. P; SANTOS, A. S; DELFINO, R. M; SILVA, A. F. N.; CAMAROTTI, M. F; SAÚDE ESCOLAR: o uso de diferentes recursos didáticos para o ensino, sensibilização e prevenção das parasitoses humanas em uma escola da Educação Básica. CONGRESSO INTERNACIONAL DE TECNOLOGIA NA EDUCAÇÃO, 13, 2015. Anais... Recife, 2015.

LOPES, C. E. A. A importância do PIBID na formação acadêmica dos graduandos em letrasinglês: uma experiência modificadora. Itinerarius Reflectionis, v. 12, n. 1, p. 1-15, 2016. http://dx.doi.org/10.5216/rir.v12i1.37132

OLIVEIRA, R. P.; LIMA, E. F.; BRITO, C. C.; BRITO, M. J. A.; PEREIRA, C. C. A. Uso do Teatro para o Ensino da Parasitologia. Form@re. Revista do Plano Nacional de Formação de Professores da Educação Básica/Universidade Federal do Piauí, v. 3, n. 1, p. 92-95, 2015. Disponível em: <http://www.ojs.ufpi.br/index.php/parfor/article/view/3693/2108>. Acesso em: 25 mar. 2016.

PASSARELLI, L. M. G. Ensino e correção na produção de textos escolares. 1. ed. São Paulo: Telos, 2012.

PEREIRA, M. L. O ensino de Ciências através do lúdico: uma metodologia experimental. João Pessoa: Universitária/UFPB, 2009.

PRODÓCIMO, E.; PRADO, G. V. T; AYOUB, E. PIBID: análise de produções publicadas em periódicos da área da educação. Atos de Pesquisa em Educação, Blumenau, v. 10, n. 2, p. 393410, 2015.

RICHARDSON, R. Pesquisa social: métodos e técnicas. 3. ed. São Paulo: Atlas, 2010. 
SANTOS, L. M. C.; ALMEIDA, W. S.; TEIXEIRA, G. B.; MACEDO, J. F.; LIMA, L. S.; SANTOS, E. J. S.; NUNES, M. M.; CARDOSO, S. C.; REIS, Y. F. S.; SUSSUCHI, E. M. A influência do PIBID no processo de formação inicial dos licenciandos em química da UFS/São Cristóvão. Scientia Plena, v. 11, n. 6, p. 1-8, 2015. Disponível em: $<$ https://www.scientiaplena.org.br/sp/article/view/2532/1231>. Acesso em: 25 mar. 2016. 